\title{
Lack of Reactive Oxygen Species Deteriorates Blood Pressure Regulation in Acute Stress
}

\author{
I. BERNÁTOVÁ ${ }^{1}$, P. BALIŠ ${ }^{1}$, R. GOGA ${ }^{2}$, M. BEHULIAK ${ }^{3}$, J. ZICHA $^{3}$, I. SEKAJ ${ }^{2}$ \\ ${ }^{1}$ Institute of Normal and Pathological Physiology, Slovak Academy of Sciences, Bratislava, Slovak \\ Republic, ${ }^{2}$ Institute of Robotics and Cybernetics, Faculty of Electrical Engineering and Information \\ Technology, Slovak University of Technology, Bratislava, Slovak Republic, ${ }^{3}$ Institute of \\ Physiology of the Czech Academy of Sciences, Prague, Czech Republic
}

Received May 14, 2016

Accepted September 5, 2016

\section{Summary}

This study investigated the contribution of reactive oxygen species (ROS) to blood pressure regulation in conscious adult male Wistar rats exposed to acute stress. Role of ROS was investigated in rats with temporally impaired principal blood pressure regulation systems using ganglionic blocker pentolinium $(P, 5 \mathrm{mg} / \mathrm{kg})$, angiotensin converting enzyme inhibitor captopril (C, $10 \mathrm{mg} / \mathrm{kg}$ ), nitric oxide synthase inhibitor L-NAME $(\mathrm{L}, 30 \mathrm{mg} / \mathrm{kg}$ ) and superoxide dismutase mimeticum tempol $(\mathrm{T}, 25 \mathrm{mg} / \mathrm{kg}$ ). Mean arterial pressure (MAP) was measured by the carotid artery catheter and inhibitors were administered intravenously. MAP was disturbed by a 3-s air jet, which increased MAP by $35.2 \pm 3.0 \%$ vs. basal MAP after the first exposure. Air jet increased MAP in captopril- and tempol-treated rats similarly as observed in saline-treated rats. In pentoliniumtreated rats stress significantly decreased MAP vs. pre-stress value. In L-NAME-treated rats stress failed to affect MAP significantly. Treatment of rats with $\mathrm{P}+\mathrm{L}+\mathrm{C}$ resulted in stressinduced MAP decrease by $17.3 \pm 1.3 \%$ vs. pre-stress value and settling time (20.1 $\pm 4.2 \mathrm{~s})$. In $\mathrm{P}+\mathrm{L}+\mathrm{C}+\mathrm{T}$-treated rats stress led to maximal MAP decrease by $26.4 \pm 2.2 \%(p<0.005$ vs. $P+L+C)$ and prolongation of settling time to $32.6 \pm 3.3 \mathrm{~s}(\mathrm{p}<0.05 \mathrm{vs}$. $\mathrm{P}+\mathrm{L}+\mathrm{C})$. Area under the MAP curve was significantly smaller in $P+L+C$ treated rats compared to $\mathrm{P}+\mathrm{L}+\mathrm{C}+\mathrm{T}$-treated ones $(167 \pm 43$ vs. $433 \pm 69$ a.u., $p<0.008$ ). In conclusion, in rats with temporally impaired blood pressure regulation, the lack of ROS resulted in greater stress-induced MAP alterations and prolongation of time required to reach new post-stress steady state.

\section{Key words}

Air-jet stress • Superoxide • Nitric oxide • Sympathetic nervous system • Renin-angiotensin system

\section{Corresponding author}

I. Bernatova, Institute of Normal and Pathological Physiology, Slovak Academy of Sciences, Sienkiewiczova 1, 81371 Bratislava, Slovak Republic. E-mail: iveta.bernatova@savba.sk

\section{Introduction}

Blood pressure (BP) is one of the principal vital signs and the maintenance of normal BP is critical in order to keep optimal oxygenation of tissues and organs in all vertebrates, including humans. That is why BP is continually controlled and regulated on optimal levels by the central, peripheral and local tissue mechanisms. All these levels of BP regulation, including endothelium-derived factors, play a significant role in the modulation of final BP level. However, among all components of BP regulatory system the sympathetic nervous system (SNS), renin-angiotensin system (RAS) and nitric oxide (NO) seem to be the most powerful regulators.

When exposed to sudden stressor the autonomic nervous system is activated for fight or flight reaction. The stress-induced increase in heart rate (HR) by sympathetic stimulation of cardiac $\beta$-adrenergic receptors is accompanied by a rise in $\mathrm{BP}$ mediated mainly by $\alpha$-adrenergic stimulation. On the other hand, NO is the major depressor factor attenuating BP. In fact, NO, well 
known neurotransmitter, neuromodulator and vasodilator, has to be released continually, to act against vasoconstriction produced by SNS and RAS, and relative NO-deficiency was observed in experimental hypertension (Kunes et al. 2004). Furthermore, all noradrenaline, NO and angiotensin II, play a significant role in BP regulation at both central and peripheral levels (Fisher et al. 2009, Reid 1992, Pechanova 2010) affecting also stress-induced pressor responses (Cordellini et al. 2006, Porter 2000). Thus, in order to maintain optimal $\mathrm{BP}$, there is a significant cross-talk among these three systems, at all levels of BP regulation, under normal conditions as well as during stress.

Reactive oxygen species (ROS), mainly superoxide, were shown to interact with RAS, SNS and NO. ROS can be produced by mitochondria, uncoupled NOS and by various oxidases (Majzunova et al. 2013). ROS were shown to activate SNS (Campese et al. 2004), the activation of RAS was shown to stimulate ROS production (Touyz 2004, Tsuda 2012) and superoxide deactivates NO in direct chemical reaction (Thomson et al. 1995), which limits NO bioavailability. Elevated levels of ROS were shown in various experimental models of hypertension as well as in hypertensive humans as described below. Unfortunately, although chronic treatment with antioxidants reduced BP in various experimental models of hypertension (Bernatova et al. 2002, Galleano et al. 2013, Vaneckova et al. 2013, Vasdev et al. 2002a,b) long-term antioxidant treatment in clinical trials produced variable cardiovascular effects (Kris-Etherton et al. 2004). Thus, the contribution of ROS-mediated mechanisms to BP regulation, both acute and chronic, is still unclear. In addition, it is very difficult to determine the exact ROS-mediated contribution to BP regulation in the presence of other major BP regulatory systems because the effect of ROS seems to be rather mild.

The aim of this study was to determine the contribution of superoxide to BP regulation in conscious normotensive rats, in which BP was disturbed by acute air-jet stress. To emphasize the role of superoxide, the function of other regulatory systems (SNS, RAS and NO) was pharmacologically attenuated. Then the integrated pressor/depressor responses induced by airjet in freely moving rats were recorded and maximal mean arterial pressure (MAP) response, settling time and area under the BP curve were determined in order to characterize the ability of organism to maintain BP at new post-stress level.

\section{Methods}

All procedures and experimental protocols were approved by the Ethical Committee of the Institute of Physiology CAS and conformed to the European Convention on Animal Protection and Guidelines on Research Animal. Adult 12-16-week male Wistar rats were used in this study. BP was determined using the catheter inserted into the carotid artery. One day before experiment, polyethylene catheters were inserted into the left carotid artery (PE 50) and the jugular vein (PE 10) under $2 \%$ isoflurane anesthesia and exteriorized in the interscapular region as described previously (Behuliak et al. 2011). Rats were allowed to recover from anesthesia for approximately 20-24 h. All experiments were performed in quiet room to avoid any non-specific stimuli affecting BP. Before experiments the rats were placed into dark plastic box of $19 \times 11 \times 7 \mathrm{~cm}$ size, attached to $\mathrm{BP}$ recording device and $\mathrm{BP}$ was allowed to stabilize for at least $30 \mathrm{~min}$. The $\mathrm{BP}$ was recorded in conscious rats using the PowerLab system (ADInstruments, Bella Vista, Australia). Systolic BP (SBP) and diastolic BP (DBP) were recorded with sampling rate 400 samples/s (i.e. sampling frequency $400 \mathrm{~Hz}$ ). Mean arterial pressure (MAP) was calculated as $\mathrm{MAP}=\mathrm{DBP}+1 / 3$ (SBP DPB). MAP data were transformed into Matlab ${ }^{\circledR}$ environment for further analysis.

Acute stress was produced by a 3-s pulse of air at the face of rat as described previously with a minor modification of exposure time (Nakamoto et al. 2007).

To attenuate particular regulation systems, the following drugs were used: SNS was inhibited by a ganglionic transmission blocking agent pentolinium (P) at a dose of $5 \mathrm{mg} / \mathrm{kg}$. RAS was attenuated by the inhibition of the angiotensin-converting enzyme by captopril (C) at a dose of $10 \mathrm{mg} / \mathrm{kg}$. NO production was attenuated by the inhibition of nitric oxide synthase activity using $\mathrm{N}^{\mathrm{G}}$-nitro-L-arginine methyl ester (L-NAME, L) in a dose of $30 \mathrm{mg} / \mathrm{kg}$. The superoxide level was reduced by tempol $(\mathrm{T})$, a radical scavenger that mimics the activity of superoxide dismutase, at a dose of $25 \mathrm{mg} / \mathrm{kg}$. All substances were dissolved in saline (S) and given to circulation via the catheter inserted into the jugular vein as i.v. bolus in a volume $1 \mathrm{ml} / \mathrm{kg}$ of body weight as described previously (Behuliak et al. 2011). All chemicals were from Sigma (Germany). 


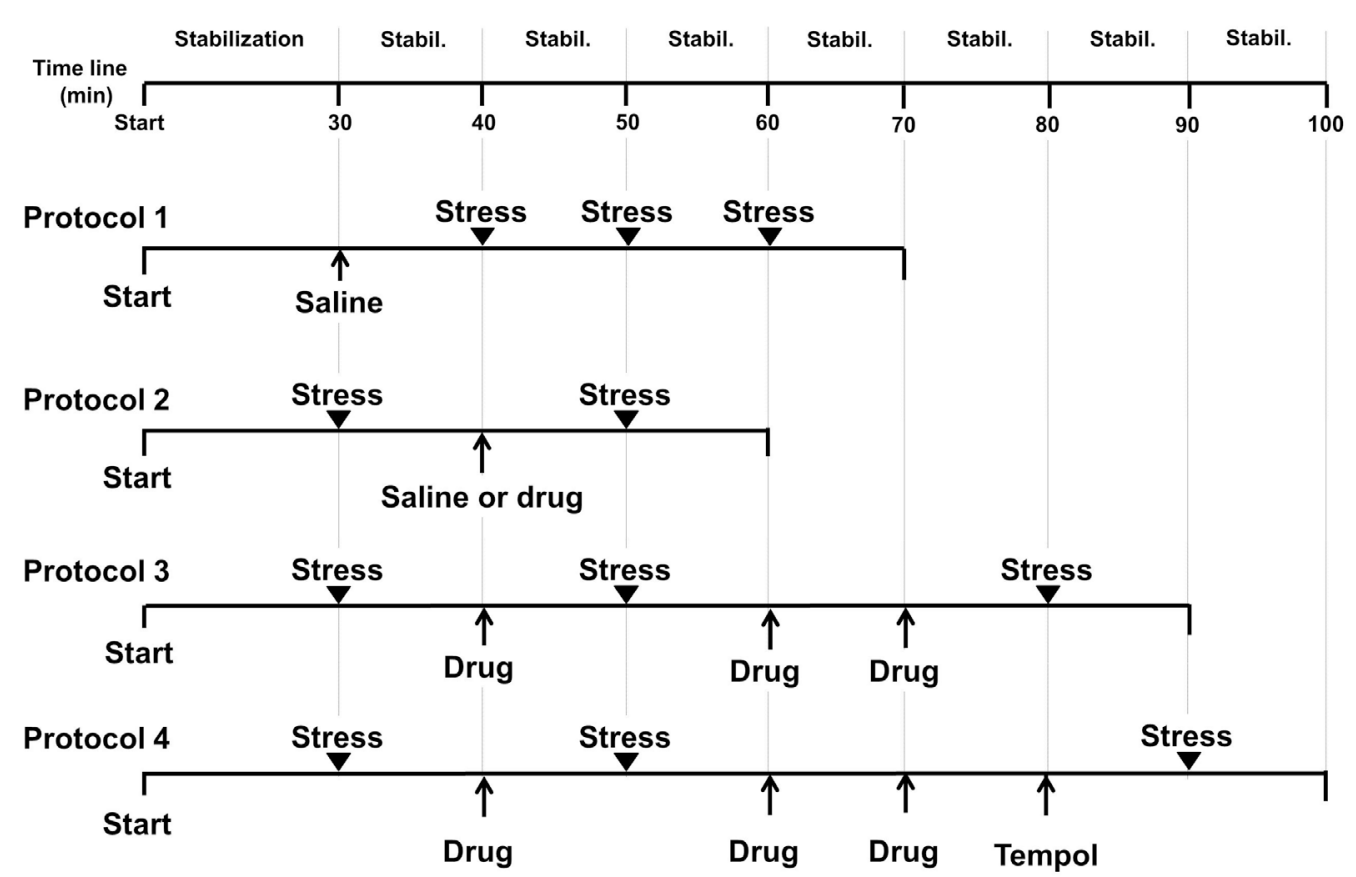

Fig. 1. Experimental protocols used in the study. Drugs were $\mathrm{N}^{\mathrm{G}}$-nitro-L-arginine methyl ester, pentolinium, captopril, and tempol and they were administered as described in Methods. Three-second air jet was used as stress (see Methods).

\section{Protocols of the experiment (Fig. 1)}

Protocol 1. Effect of stress repetition: Possible attenuation of the air-jet-induced changes of MAP was investigated by three repetitions of air jet in 10-min intervals in 10 rats (Figs 2A, B, C).

Protocol 2. The effect of individual inhibitors (i.e. drugs) was investigated as follows: After $30 \mathrm{~min}$ stabilization of BP, rats were exposed to air jet to determine the response of each rat to this stimulus. Then BP was allowed to stabilize for $10 \mathrm{~min}$. The effect of individual inhibitors was detected by administration of $\mathrm{S}$, $\mathrm{P}, \mathrm{L}, \mathrm{C}$ and T, respectively. Basal MAP was determined in stable 10 -s period, $1 \mathrm{~min}$ before drug administration, and then during the tenth min after drug administration. Then rats were exposed to the second air jet to determine the effect of the individual substances on air-jet-induced MAP responses. MAP was determined between 1-5 s after stress as the maximal change of BP (Fig. 3).

Protocol 3. At the end of the protocol 2, the next two inhibitors (different from the first one and T) were administered in random order in 10-min intervals. After the third inhibitor, BP was allowed to stabilize for next $10 \mathrm{~min}$. Average 10-s value of MAP determined during the tenth min after the third inhibitor (i.e. after the administration of $\mathrm{P}+\mathrm{C}+\mathrm{L}$ ) was taken as pre-stress MAP value. Then the third 3-s air jet was delivered and MAP recovery transient process was continuously recorded for 10 min (Fig. 4A).
Protocol 4. In a separate group of rats the protocol 2 and 3 were repeated but $\mathrm{T}$ was administered as the fourth substance (i.e. $\mathrm{P}+\mathrm{C}+\mathrm{L}+\mathrm{T}$ ) before the third air jet (Fig. 4B).

Air-jet stress-induced MAP time-responses were expressed as $\triangle \mathrm{MAP}(\%)$ with respect to MAP determined during the approximately 20 -s period before the respective air-jet stress, i.e. the average MAP before stress was calculated from approximately 8000 samples. The responses were analyzed by determination of the following three parameters: 1) the maximal stressinduced peak deviation of MAP $\left(\mathrm{P}_{\max }\right)$, 2) settling time $\left(\mathrm{t}_{\mathrm{s}}\right)$ expressed in seconds, 3) area under the MAP curve (AUC), expressed in arbitrary units (a.u.) and 4) maximal MAP deviation detected during the post-stress steady state $(\delta)$, expressed as percentage change with regard to $\mathrm{P}_{\max }$ (Fig. 2A).

$\mathrm{P}_{\max }$ was defined as the difference between the maximal stress-induced MAP compared to MAP determined during the 20 -s period before the given air-jet stress. Settling time $\left(t_{s}\right)$ was defined as the time interval between the start of the air-jet stress and the moment when the MAP reached and stayed within the MAP error band $\mathrm{E}_{\mathrm{ss}}$ (Tay et al. 1997). $\mathrm{E}_{\mathrm{ss}}$ was defined as the interval $\left(M A P_{s s}-\delta ; M A P_{s s}+\delta\right)$ where $\delta$ represents the maximal MAP deviation from the average MAP during the steady state $\left(\mathrm{MAP}_{\mathrm{ss}}\right)$. In this study, $\mathrm{MAP}_{\mathrm{ss}}$ was determined during the time period between approximately 40-60 s 
after air jet, and it was calculated as the average MAP value from approximately 8000 samples of MAP. Because the oscillation amplitudes of MAP during the steady state were variable in particular rats, the size of $\delta$ was determined in each rat individually.

The area under the MAP curve (AUC) was calculated as the area which is bounded by the MAP curve and by the $\mathrm{MAP}_{\mathrm{ss}}$ value during the settling time $t_{\mathrm{s}}$, expressed in arbitrary units

$$
A U C=\int_{0}^{t_{s}}\left(\left|M A P-M A P_{s s}\right|\right)
$$

The equation (1) describes the continuous-time measurement evaluation. In this study the MAP was measured in discrete form with the sampling period $\mathrm{T}$, where $T=1 / f$ and the sampling frequency $f=400 \mathrm{~Hz}$. In the discrete-time domain the equation (1) can be transformed to

$A U C=\sum_{i=1}^{N} T\left(\left|M A P_{i}-M A P_{s s, i}\right|\right)$

where $\mathrm{N}$ is the number of samples during settling time $t_{\mathrm{s}}$.

\section{Statistical analysis}

The effect of repeated air-jet exposure and the effect of individual inhibitors and stress were analyzed by one-way ANOVA and Dunnet's post-hoc test. Between the groups differences $(\mathrm{L}+\mathrm{P}+\mathrm{C}$ vs. $\mathrm{L}+\mathrm{P}+\mathrm{C}+\mathrm{T})$ were analyzed using Student's t-test for independent samples. The significance level was set at $5 \%(\alpha=0.05)$. All values were presented as the mean \pm SEM. Data were analyzed with Statistica ${ }^{\circledR} 7.0$ (Stat Soft, Inc., USA), GraphPad Prism 5.0 (GraphPad Software, Inc., USA) and Matlab ${ }^{\circledR}$ R2010a (Mathworks, Inc, USA).
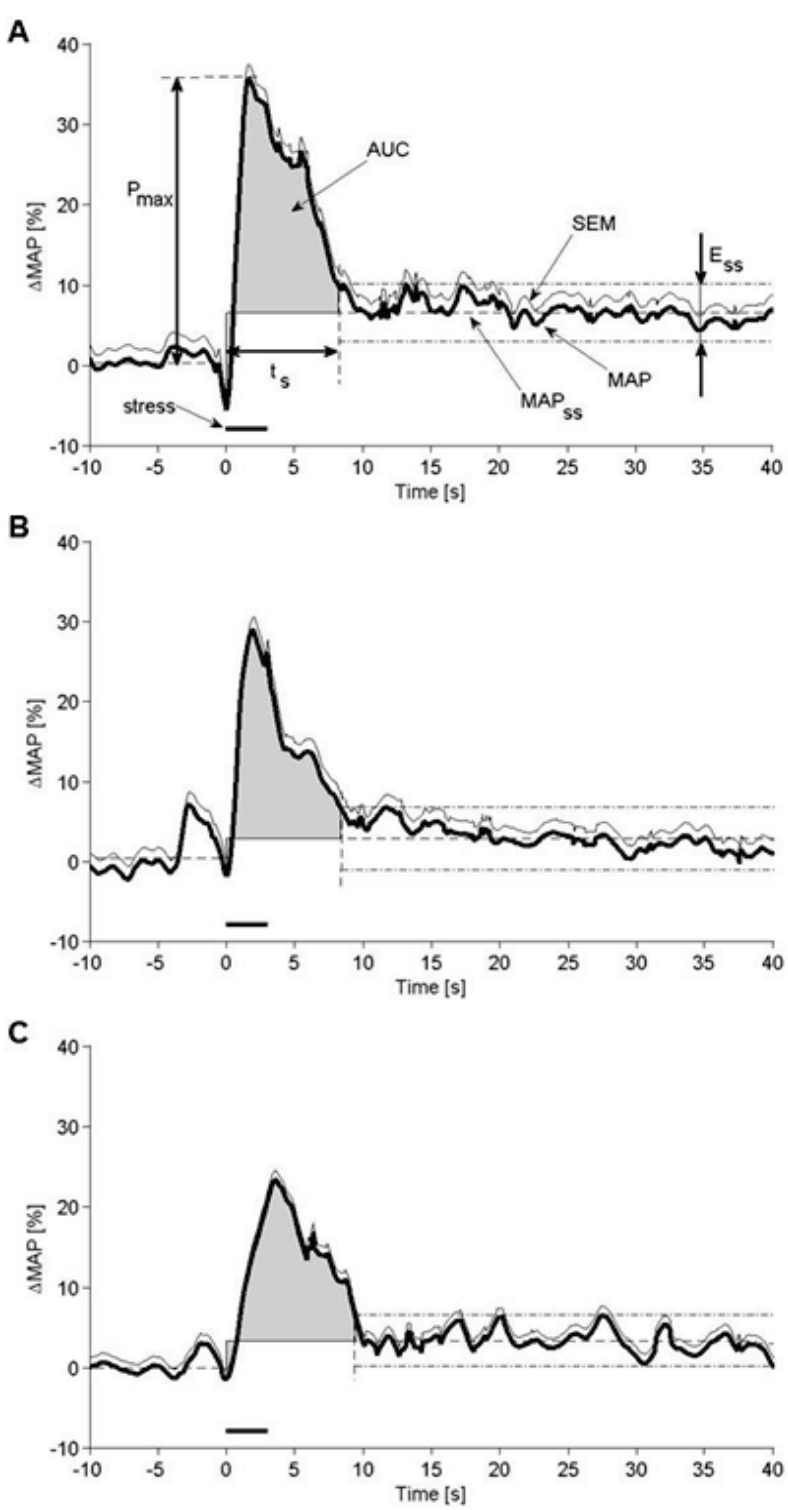

Fig. 2. Average waveforms (black line) of the air-jet stressinduced changes of mean arterial pressure (MAP) and its standard error of mean (SEM, thin line) after the first (A), the second (B) and the third (C) air-jet stress, $n=10$. AUC - area under the MAP curve, $E_{s s}-M_{\text {AP }}$ error band, $M_{\text {AP }}$ - MAP steady state, $P_{\max }-$ maximal $\triangle M A P$ vs. pre-stress, $t_{s}-$ settling time. See graphic explanations of the $P_{\max }, t_{s}$ and AUC in the Figure $2 A$.

Table 1. Characteristics of mean arterial pressure regulation induced by air-jet stress itself (Stress $1-$ Stress 3 ) and air-jet stress in the $\mathrm{P}+\mathrm{L}+\mathrm{C}$ - and $\mathrm{P}+\mathrm{L}+\mathrm{C}+\mathrm{T}$-treated rats.

\begin{tabular}{lllll}
\hline Group & $\mathbf{P}_{\max }(\mathbf{\%})$ & $\mathbf{t}_{\mathbf{s}}(\mathbf{s})$ & AUC (a.u.) & $\boldsymbol{\delta}\left(\mathbf{\%} \mathbf{P}_{\max }\right)$ \\
\hline Stress 1 $(n=10)$ & $35.2 \pm 3.0$ & $8.2 \pm 1.2$ & $143 \pm 31$ & $17.3 \pm 2.2$ \\
Stress 2 $(n=10)$ & $28.4 \pm 3.4$ & $8.4 \pm 2.1$ & $128 \pm 33$ & $20.1 \pm 3.1$ \\
Stress 3 $(n=10)$ & $23.3 \pm 3.0^{+}$ & $9.4 \pm 1.9$ & $93 \pm 17$ & $28.7 \pm 2.8^{+}$ \\
$P+L+C(n=8)$ & $-17.3 \pm 1.3$ & $21 \pm 4$ & $167 \pm 43$ & $-6.6 \pm 0.9$ \\
$P+L+C+T(n=10)$ & $-26.4 \pm 2.2^{*}$ & $33 \pm 3^{*}$ & $433 \pm 69^{*}$ & $-10.3 \pm 2.8$ \\
\hline
\end{tabular}

$\mathrm{P}_{\max }$ - maximal mean arterial pressure (MAP) change in percentage of pre-stress MAP, $t_{s}-$ settling time, AUC - area under the blood pressure curve, $\delta$ - maximal MAP deviation from the average value of post-stress MAP, L $-N^{G}$-nitro-L-arginine methyl ester, $\mathrm{P}$ - pentolinium, $\mathrm{C}$ - captopril, $\mathrm{T}-$ tempol. Results are mean $\pm \mathrm{SEM} .{ }^{+} \mathrm{p}<0.05$ vs. Stress $1,{ }^{*} \mathrm{p}<0.05$ vs. the $\mathrm{P}+\mathrm{L}+\mathrm{C}$ group. 


\section{Results}

The first air-jet-induced MAP responses were relatively consistent in saline-treated control rats with $\mathrm{P}_{\max }$ about $35 \%$ vs. pre-stress value, settling time about $8 \mathrm{~s}$, AUC approximately 143 a.u. and steady-state error $\delta$ about $17 \%$ of $\mathrm{P}_{\max }$ (Fig. 2A, Table 1). These parameters did not change significantly after the second air-jet stress (Fig. 2B, Table 1). The third exposure to air jet led to the significant reduction of the $\mathrm{P}_{\max }(\mathrm{p}<0.04)$ and elevation the steady-state error $(p<0.04)$ vs. the first stress, while the other two parameters were altered non-significantly (Fig. 2C, Table 1).

Saline itself had no effect on basal MAP and stress-induced MAP changes compared to non-injected rats (Fig. 3). Ten minutes after the administration of pentolinium or captopril, MAP decreased by approximately $25 \%$ and $10 \%$ vs. basal values, respectively, ( $\mathrm{p}<0.05$ for both). L-NAME itself increased MAP by approximately $38 \%$ vs. basal values $(p<0.001)$. Tempol itself failed to affect MAP significantly (Fig. 3).

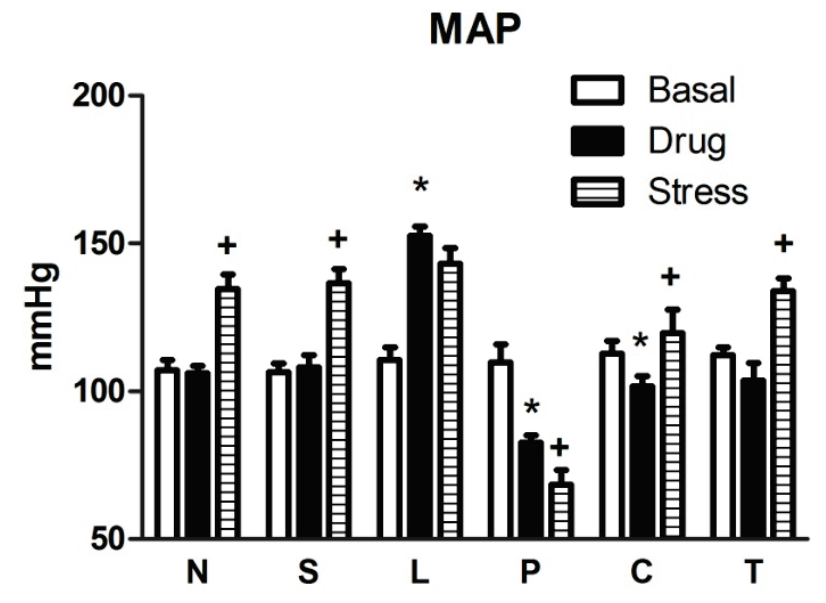

Fig. 3. The effect of individual substances on mean arterial pressure (MAP) and air-jet-induced MAP changes after pretreatment with the given drug. white bar - basal MAP determined between 1-2 min before drug application, black bar MAP determined between 9-10 min after the treatment with $S, P$, $C$, $L$ and $T$, respectively, stripped bar - maximal MAP determined in period of $1-5 \mathrm{~s}$ post stress in rats pretreated with $S, P, C, L$ and $\mathrm{T}$, respectively. $\mathrm{S}$ - saline, $\mathrm{L}-\mathrm{N}^{\mathrm{G}}$-nitro-L-arginine methyl ester, $\mathrm{N}$ - non-injected rats, $\mathrm{P}$ - pentolinium, C - captopril, $\mathrm{T}$ - tempol. Results are mean \pm SEM. * $\mathrm{p}<0.05$ vs. basal, $+\mathrm{p}<0.05$ vs. treatment, $\mathrm{n}=5-7$.
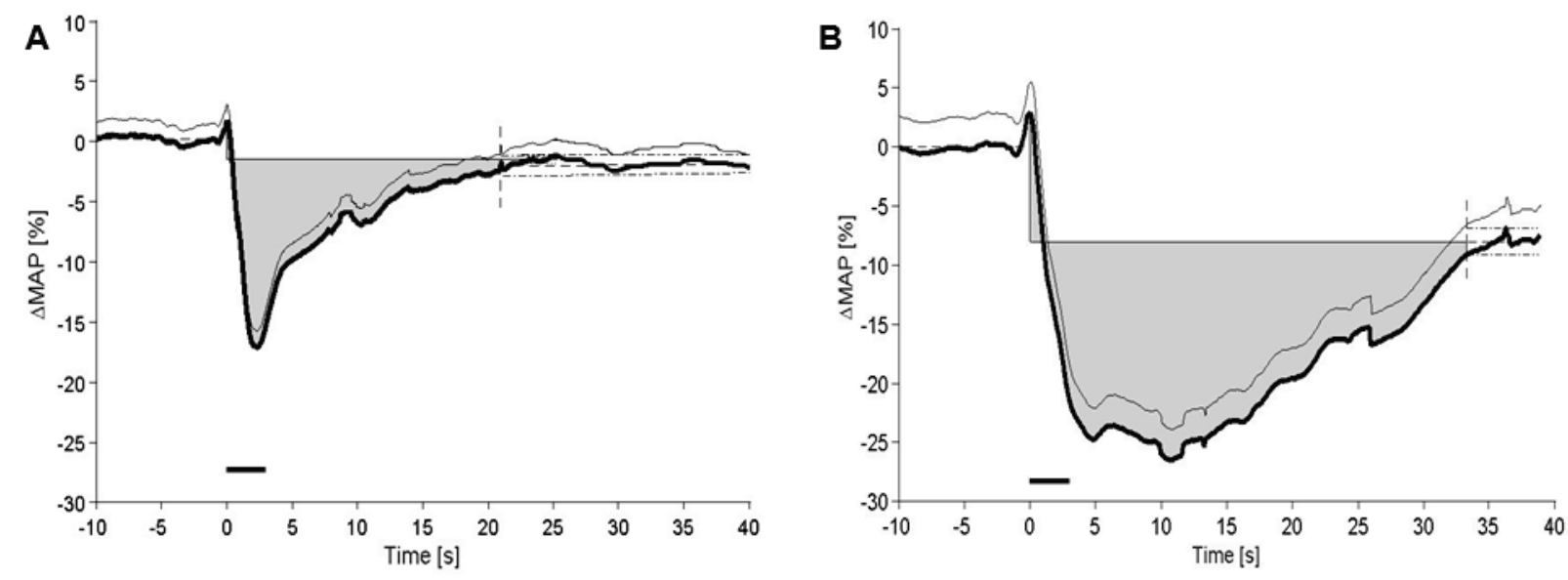

Fig. 4. The effect of air-jet stress on mean arterial pressure (MAP) in rats pretreated with $L+P+C$ (A) and pretreated with $L+P+C+T$ (B). $\mathrm{L}-\mathrm{N}^{\mathrm{G}}$-nitro-L-arginine methyl ester, $\mathrm{P}$ - pentolinium, $\mathrm{C}$ - captopril, $\mathrm{T}$ - tempol. Black line - average waveform of the mean arterial pressure and its standard error of mean (SEM, thin line). The values of maximal MAP, settling time and area under the MAP curve are written in the Table 1. See Figure 2A for graphic explanations of these variables.

Exposure of captopril-treated rats to air jet led to approximately $16 \%$ increase of MAP vs. pre-stress levels $(\mathrm{p}<0.05)$ (Fig. 3). Similarly, MAP of tempol-treated rats exposed to air jet increased by approximately $29 \%$ vs. pre-stress levels $(\mathrm{p}<0.01)$. In pentolinium-pretreated rats MAP decreased significantly by approximately $17 \%$ vs. pre-stress levels $(\mathrm{p}<0.01)$. Interestingly, in L-NAMEtreated rats the acute stress failed to affect MAP significantly, however, a decreasing trend of MAP was observed in these rats (Fig. 3).

Pretreatment of rats with $\mathrm{P}+\mathrm{L}+\mathrm{C}$ led to stressinduced MAP response characterized by maximal decrease of MAP by about $17 \%$ vs. pre-stress, $\mathrm{t}_{\mathrm{s}}$ approximately $21 \mathrm{~s}$ and AUC about 167 a.u. (Fig. 4A, Table 1). Co-administration of tempol to $\mathrm{P}+\mathrm{L}+\mathrm{C}$-treated rats let to more pronounce stress-induced changes of MAP vs. the $\mathrm{P}+\mathrm{L}+\mathrm{C}$ group in all parameters determined (Fig. 4B, Table 1). 


\section{Discussion}

This study investigated the contribution of ROS to regulation of BP in stress reaction induced by sudden aversive stimulus produced by air jet. We found that in the rats in which major BP regulatory systems were ineffective, the lack of ROS resulted in greater changes of MAP and prolongation of settling time compared with those determined in rats with unaltered ROS level. As this observation was done after acute air-jet stress in rats in which SNS, RAS and NO-mediated mechanisms were attenuated, it is assumed that the effect of ROS could be associated with other regulatory mechanisms related to the local endothelial factors.

We used acute air jet as the stimulus to induce stress reaction associated with prominent BP increase. Air-jet stress is an environmental stressor resulting in psychoemotional stress, which causes the characteristic pattern of the classic defense reaction with an increase in MAP, heart rate and renal sympathetic nerve activity (Davisson et al. 1996, Kanbar et al. 2007, Yamazato et al. 2006).

In this study, the second repetition of air jet was associated with only non-significant reduction of maximal MAP increase, settling time and area under the MAP curve, i.e. parameters that characterize the return of BP to new post-stress equilibrium. However, the third airjet stress led to reduction of maximal MAP increase suggesting gradual habituation of rats to this stimulus. On the other hand, no reductions of BP responses were observed using 1-s air jet in 5-min interval (Davisson et al. 1996) or when the stimulus was delivered in different days (Fuchs et al. 1998). Significant habituation, which is a fundamental learning in which the organism learns not to respond to redundant non-significant stimuli (Groves and Thompson 1970), was observed in all parameters determined after the fifth exposure to air jet in our preliminary study (data not shown).

There is evidence that interaction of RAS and ROS play an important role in the control of cardiovascular functions, including stress-induced cardiovascular responses. In this study, captopril reduced baseline MAP significantly. On the other hand, tempol had only minor effect on baseline BP. In rats pretreated with intravenous administration of captopril and tempol, respectively, air jet led to $\mathrm{BP}$ increase similar to that observed in saline-treated rats, suggesting that RAS and ROS in normotensive rats had no critical impact on stress-induced pressor responses in this experimental setup. In previous studies, tempol administered intravenously caused dose-dependent reductions in blood pressure of hypertensive rodent models but less effect was found in normotensive rats (Wilcox and Pearlman 2008, Zicha et al. 2001). In rabbits, tempol-pretreatment reduced angiotensin II-induced pressor responses as well as air-jet-induced MAP increase (Mayorov et al. 2004).

Inhibition of ganglionic transmission by pentolinium, which inhibits nicotinic acetylcholine receptors in sympathetic ganglia and thus inhibits the release of noradrenaline from nerve terminus, was associated with decrease of basal BP and inversion of airjet-induced MAP response. After the blockade of nicotinic receptors by pentolinium the smooth muscle relaxation and BP decrease may occur due to $\beta_{2}$-receptormediated vasorelaxation likewise it was observed in cocaine-induced BP responses (Poon and van den Buuse 1998). Thus SNS has clearly decisive influence on air-jet stress-induced MAP responses. Similar findings on the role of SNS in air-jet stress-induced MAP changes were observed using losartan (angiotensin II receptor antagonist) and prazosin ( $\alpha_{1}$-adrenoceptor blocker) (Gaudet et al. 1996).

Interestingly, air-jet stress failed to increase MAP when rats were pre-treated with L-NAME. As a lack of NO due to chronic NOS inhibition is associated with elevation of BP (Bernatova et al. 2002), one would expect rather more pronounced increase of $\mathrm{BP}$ in L-NAME-treated vs. saline-treated rats than a mild BP decrease detected in our study. The absence of MAP increase after air jet was observed also by Davisson et al. (1996) who found that L-NAME did not interfere with the central processing of the air-jet or the resultant changes in autonomic nerve activity. The authors suggested the release of pre-existing or de novo synthesized NO-related factor(s) from vascular endothelium and postganglionic NO synthase-containing sympathetic nerves, which may regulate vascular tone under conditions in which NO synthesis is temporarily compromised (Davisson et al. 1996). The absence of airjet-induced BP increase after L-NAME-treatment was observed also by Moraes-Neto et al. (2014) who observed attenuated BP rise following a 60-min restraint stress after bilateral injection of an NMDA receptor antagonist, NOS inhibitor or NO scavenger into the dorsal hippocampus. Their results suggest that the activation glutamatergic and nitrergic neurotransmission within the hippocampus may play a role in autonomic modulation acute stress (Moraes-Neto et al. 2014). Thus the exact 
mechanism by which L-NAME attenuates pressor responses induced by acute stress needs further investigations.

This study was focused on determination of the role of ROS in BP regulation in terms of maximal stressinduced BP changes and time required to achieve a new balance as well as by $\delta$ coefficient that represents the maximal MAP deviation from the average MAP during the post-stress steady state. These parameters are usually used to characterize regulation processes, i.e. ability of the system to keep given variable in defined range of values. By now ROS were investigated and discussed mainly as one of the factors involved in development and/or maintenance of high blood pressure as increased levels of ROS may lead to oxidative stress. Oxidative stress was observed in patients with essential hypertension, renovascular hypertension, malignant hypertension or pre-eclampsia (Higashi et al. 2002, Lip et al. 2002, Wang et al. 2009) as well as in various animal experimental models of hypertension such as angiotensin II-induced hypertension (Wakui et al. 2013), endothelin1-induced hypertension (Elmarakby et al. 2005), Dahl salt-induced hypertension (Zhou et al. 2006, Zicha et al. 2001), deoxycorticosterone acetate (DOCA)-salt induced hypertension (Gomez-Guzman et al. 2012, Viel et al. 2008), fructose-induced (Al-Awwadi et al. 2005, Korandji et al. 2011) or lead-induced hypertension (Vaziri and Sica 2004). Elevated ROS production was observed in the spontaneously hypertensive rats (Condezo-Hoyos et al. 2012, Slezak et al. 2014, Virdis et al. 2009). In addition, high BP per se was found to increase arterial superoxide production primarily by activating directly a NAD(P)H oxidase pathway, but also, in part, via activation of the local renin-angiotensin system (Ungvari et al. 2004).

Mechanism of ROS action was found to be associated also with the reduction of bioavailable NO (Vaziri and Sica 2004, Zhou et al. 2006) and altered local vascular mechanisms. In addition to superoxide, other ROS, such as hydrogen peroxide and hydroxyl anion, were shown to affect endothelial function and to modify vascular tone of the arteries depending on oxidative status (Puri et al. 2013). ROS were shown to activate cyclooxygenase concurrently with the inhibition of prostacyclin-mediated relaxation that results in accentuation of thromboxane $\mathrm{A}_{2}$-induced constriction (Bachschmid et al. 2013, Korbecki et al. 2013). Furthermore, ROS inhibit vascular smooth muscle cell hyperpolarization and reduces $\mathrm{H}_{2} \mathrm{~S}$-mediated relaxation, supporting the arterial constriction. The effect of ROS on vascular function may be accentuated after inhibition of NO production that may result in elevated bioavailability of superoxide (Testai et al. 2015).

In this study, we used an experimental model in which SNS, RAS and NO production were attenuated, although the influence of these systems may be still present in the minor extent. For example, under the conditions of pharmacological inhibition of adrenoreceptors, the co-transmitters such as ATP and NPY may still partially supply peripheral signal transmission (Racchi et al. 1999). Similarly, angiotensin II can be produced by angiotensin-converting enzymeindependent pathways that provide an alternative source of angiotensin II (Li et al. 2004). Furthermore, NO may be released from S-nitrosothiols to restore, at least partially, NO-dependent relaxation (Drobná et al. 2015, Maron et al. 2013). Moreover, lack of NO-dependent relaxation can be compensated by other endotheliumderived relaxing factors (Behuliak et al. 2011). These supplementary mechanisms can be effective in the regulation of BP after SNS, RAS and/or NOS inhibition and they can affect stress-induced $\mathrm{BP}$ responses as it was observed in this study in $\mathrm{P}+\mathrm{C}+\mathrm{L}$-treated rats. In addition, this study showed that ROS-mediated mechanisms are involved in acute post-stress regulation of BP. As it is mentioned above, ROS were described as endotheliumderived contracting factors in various models of hypertension (Bernatova 2014), thus their local vasoconstricting effects may play a significant role in BP recovery under condition when SNS- and RAS-mediated mechanisms are inhibited.

In conclusion, our results showed that the lack of ROS resulted in greater stress-induced MAP decrease and prolongation of time required to reach new post-stress steady state in rats with temporally impaired blood pressure regulation. Thus, ROS-mediated mechanisms may participate in short-term local regulation of BP when main constrictor systems are temporarily ineffective. Our data suggest the involvement of local vascular mechanisms yet the exact signal pathways needs to be clarified in further studies.

\section{Conflict of Interest}

There is no conflict of interest.

\section{Acknowledgements}

The authors thank Mrs. J. Petova and M. Majzunova, $\mathrm{PhD}$. for their technical assistance. This study was 
supported by the grants APVV-0523-10, VEGA 2/0084/14, VEGA 1/0475/16, Ministry of Health of the Czech Republic 15-25396A and inter-academic cooperation contract AVCR-16-18. The infrastructure used in this study was partially supported by the "ITMS 26240120020 - Establishment of the Centre for the Research on Composite Materials for Structural, Engineering and Medical Applications - CEKOMAT II".

\section{References}

AL-AWWADI NA, ARAIZ C, BORNET A, DELBOSC S, CRISTOL JP, LINCK N, AZAY J, TEISSEDRE PL, CROS G: Extracts enriched in different polyphenolic families normalize increased cardiac NADPH oxidase expression while having differential effects on insulin resistance, hypertension, and cardiac hypertrophy in high-fructose-fed rats. J Agric Food Chem 53: 151-157, 2005.

BACHSCHMID MM, SCHILDKNECHT S, MATSUI R, ZEE R, HAEUSSLER D, COHEN RA, PIMENTAL D, LOO B: Vascular aging: chronic oxidative stress and impairment of redox signaling-consequences for vascular homeostasis and disease. Ann Med 45: 17-36, 2013.

BEHULIAK M, PINTEROVA M, KUNES J, ZICHA J: Vasodilator efficiency of endogenous prostanoids, Ca ${ }^{2+}$ activated $\mathrm{K}^{+}$channels and nitric oxide in rats with spontaneous, salt-dependent or NO-deficient hypertension. Hypertens Res 34: 968-975, 2011.

BERNATOVA I: Endothelial dysfunction in experimental models of arterial hypertension: cause or consequence? Biomed Res Int 2014: 598271, 2014.

BERNATOVA I, PECHANOVA O, BABAL P, KYSELA S, STVRTINA S, ANDRIANTSITOHAINA R: Wine polyphenols improve cardiovascular remodeling and vascular function in NO-deficient hypertension. Am J Physiol Heart Circ Physiol 282: H942-H948, 2002.

CAMPESE VM, YE S, ZHONG H, YANAMADALA V, YE Z, CHIU J: Reactive oxygen species stimulate central and peripheral sympathetic nervous system activity. Am J Physiol Heart Circ Physiol 287: H695-H703, 2004.

CONDEZO-HOYOS L, ARRIBAS SM, ABDERRAHIM F, SOMOZA B, GIL-ORTEGA M, DIAZ-GIL JJ, CONDE MV, SUSIN C, GONZALEZ MC: Liver growth factor treatment reverses vascular and plasmatic oxidative stress in spontaneously hypertensive rats. J Hypertens 30: 1185-1194, 2012.

CORDELLINI S, NOVO R, LANZA JU: Exposure to stress differential vascular adaptive response in spontaneously hypertensive and Wistar rats: Role of nitric oxide, and prehypertensive and hypertensive states. Life Sci 79: 646-653, 2006.

DAVISSON RL, SHAFFER RA, JOHNSON AK, LEWIS SJ: Use-dependent loss of active sympathetic neurogenic vasodilation after nitric oxide synthase inhibition in conscious rats. Evidence for the presence of preformed stores of nitric oxide-containing factors. Hypertension 28: 347-353, 1996.

DROBNA M, MISAK A, HOLLAND T, KRISTEK F, GRMAN M, TOMASOVA L, BERENYIOVA A, CACANYIOVA S, ONDRIAS K: Captopril partially decreases the effect of $\mathrm{H}_{2} \mathrm{~S}$ on rat blood pressure and inhibits $\mathrm{H}_{2} \mathrm{~S}$-induced nitric oxide release from S-nitrosoglutathione. Physiol Res 64: 479-486, 2015.

ELMARAKBY AA, LOOMIS ED, POLLOCK JS, POLLOCK DM: NADPH oxidase inhibition attenuates oxidative stress but not hypertension produced by chronic ET-1. Hypertension 45: 283-287, 2005.

FISHER JP, YOUNG CN, FADEL PJ: Central sympathetic overactivity: maladies and mechanisms. Auton Neurosci 148: 5-15, 2009.

FUCHS LC, HOQUE AM, CLARKE NL: Vascular and hemodynamic effects of behavioral stress in borderline hypertensive and Wistar-Kyoto rats. Am J Physiol 274: 375-382, 1998.

GALLEANO M, BERNATOVA I, PUZSEROVA A, BALIS P, SESTAKOVA N, PECHANOVA O, FRAGA CG: (-)-Epicatechin reduces blood pressure and improves vasorelaxation in spontaneously hypertensive rats by NO-mediated mechanism. IUBMB Life 65: 710-715, 2013.

GAUDET E, BLANC J, ELGHOZI JL: Role of angiotensin II and catecholamines in blood pressure variability responses to stress in SHR. Am J Physiol 270: R1265-R1272, 1996.

GOMEZ-GUZMAN M, JIMENEZ R, SANCHEZ M, ZARZUELO MJ, GALINDO P, QUINTELA AM, LOPEZSEPULVEDA R, ROMERO M, TAMARGO J, VARGAS F, PEREZ-VIZCAINO F, DUARTE J: Epicatechin lowers blood pressure, restores endothelial function, and decreases oxidative stress and endothelin-1 and NADPH oxidase activity in DOCA-salt hypertension. Free Radic Biol Med 52: 70-79, 2012. 
GROVES PM, THOMPSON RF: Habituation: a dual-process theory. Psychol Rev 77: 419-450, 1970.

HIGASHI Y, SASAKI S, NAKAGAWA K, MATSUURA H, OSHIMA T, CHAYAMA K: Endothelial function and oxidative stress in renovascular hypertension. $N$ Engl J Med 346: 1954-1962, 2002.

KANBAR R, OREA V, BARRES C, JULIEN C: Baroreflex control of renal sympathetic nerve activity during air-jet stress in rats. Am J Physiol Regul Integr Comp Physiol 292: R362-R367, 2007.

KORANDJI C, ZELLER M, GUILLAND JC, COLLIN B, LAUZIER B, SICARD P, DUVILLARD L, GOIRAND F, MOREAU D, COTTIN Y, ROCHETTE L, VERGELY C: Time course of asymmetric dimethylarginine (ADMA) and oxidative stress in fructose-hypertensive rats: a model related to metabolic syndrome. Atherosclerosis 214: 310-315, 2011.

KORBECKI J, BARANOWSKA-BOSIACKA I, GUTOWSKA I, CHLUBEK D: The effect of reactive oxygen species on the synthesis of prostanoids from arachidonic acid. J Physiol Pharmacol 64: 409-421, 2013.

KRIS-ETHERTON PM, LICHTENSTEIN AH, HOWARD BV, STEINBERG D, WITZTUM JL: Antioxidant vitamin supplements and cardiovascular disease. Circulation 110: 637-641, 2004.

KUNES J, HOJNA S, KADLECOVA M, DOBESOVA Z, RAUCHOVA H, VOKURKOVA M, LOUKOTOVA J, PECHANOVA O, ZICHA J: Altered balance of vasoactive systems in experimental hypertension: the role of relative NO deficiency. Physiol Res $\mathbf{5 3}$ (Suppl 1): S23-S34, 2004.

LI M, LIU K, MICHALICEK J, ANGUS JA, HUNT JE, DELL'ITALIA LJ, FENELEY MP, GRAHAM RM, HUSAIN A: Involvement of chymase-mediated angiotensin II generation in blood pressure regulation. J Clin Invest 114: 112-120, 2004.

LIP GYH, EDMUNDS E, NUTTALL SL, LANDRAY MJ, BLANN AD, BEEVERS DG. Oxidative stress in malignant and non-malignant phase hypertension. J Hum Hypertens 16: 333-336, 2002.

MAJZUNOVA M, DOVINOVA I, BARANCIK M, CHAN JY: Redox signaling in pathophysiology of hypertension. J Biomed Sci 20: 69, 2013.

MARON BA, TANG SS, LOSCALZO J: S-nitrosothiols and the S-nitrosoproteome of the cardiovascular system. Antioxid Redox Signal 18: 270-287, 2013.

MAYOROV DN, HEAD GA, DE MR: Tempol attenuates excitatory actions of angiotensin II in the rostral ventrolateral medulla during emotional stress. Hypertension 44: 101-106, 2004.

MORAES-NETO TB, SCOPINHO AA, BIOJONE C, CORREA FM, RESSTEL LB: Involvement of dorsal hippocampus glutamatergic and nitrergic neurotransmission in autonomic responses evoked by acute restraint stress in rats. Neuroscience 258: 364-373, 2014.

NAKAMOTO M, OHYA Y, SAKIMA A, YAMAZATO M, TAKISHITA S: Azelnidipine attenuates cardiovascular and sympathetic responses to air-jet stress in genetically hypertensive rats. Hypertens Res 30: 359-366, 2007.

PECHANOVA O: Contribution of central nervous system to hypertension: role of angiotensin II and nitric oxide. Act Nerv Super Rediviva 52: 223-227, 2010.

POON J, VAN DEN BUUSE M: Autonomic mechanisms in the acute cardiovascular effects of cocaine in conscious rats. Eur J Pharmacol 363: 147-152, 1998.

PORTER JP: Contribution of central ANG II to acute stress-induced changes in baroreflex function in young rats. Am J Physiol Regul Integr Comp Physiol 279: R1386-R1391, 2000.

PURI N, ZHANG F, MONU SR, SODHI K, BELLNER L, LAMON BD, ZHANG Y, ABRAHAM NG, NASJLETTI A: Antioxidants condition pleiotropic vascular responses to exogenous $\mathrm{H}_{2} \mathrm{O}_{2}$ : role of modulation of vascular TP receptors and the heme oxygenase system. Antioxid Redox Signal 18: 471-480, 2013.

RACCHI H, IRARRAZABAL MJ, HOWARD M, MORAN S, ZALAQUETT R, HUIDOBRO-TORO JP: Adenosine 5'-triphosphate and neuropeptide $\mathrm{Y}$ are co-transmitters in conjunction with noradrenaline in the human saphenous vein. Br J Pharmacol 126: 1175-1185, 1999.

REID IA: Interactions between ANG II, sympathetic nervous system, and baroreceptor reflexes in regulation of blood pressure. Am J Physiol 262: E763-E778, 1992.

SLEZAK P, PUZSEROVA A, BALIS P, SESTAKOVA N, MAJZUNOVA M, DOVINOVA I, KLUKNAVSKY M, BERNATOVA I: Genotype-related effect of crowding stress on blood pressure and vascular function in young female rats. Biomed Res Int 2014: 413629, 2014.

TAY TT, MAREELS I, MOORE JB: High Performance Control. Springer Science \& Business Media, Birkhäuser, 1997, p. 93. 
TESTAI L, D'ANTONGIOVANNI V, PIANO I, MARTELLI A, CITI V, DURANTI E, VIRDIS A, BLANDIZZI C, GARGINI C, BRESCHI MC, CALDERONE V. Different patterns of $\mathrm{H}_{2} \mathrm{~S} / \mathrm{NO}$ activity and cross-talk in the control of the coronary vascular bed under normotensive or hypertensive conditions. Nitric Oxide 47: 25-33, 2015.

THOMSON L, TRUJILLO M, TELLERI R, RADI R: Kinetics of cytochrome $\mathrm{c}^{2+}$ oxidation by peroxynitrite: implications for superoxide measurements in nitric oxide-producing biological systems. Arch Biochem Biophys 319: 491-497, 1995.

TOUYZ RM: Reactive oxygen species and angiotensin II signaling in vascular cells - implications in cardiovascular disease. Braz J Med Biol Res 37: 1263-1273, 2004.

TSUDA K: Renin-angiotensin system and sympathetic neurotransmitter release in the central nervous system of hypertension. Int J Hypertens 2012: 474870, 2012.

UNGVARI Z, CSISZAR A, KAMINSKI PM, WOLIN MS, KOLLER A: Chronic high pressure-induced arterial oxidative stress: involvement of protein kinase C-dependent $\mathrm{NAD}(\mathrm{P}) \mathrm{H}$ oxidase and local renin-angiotensin system. Am J Pathol 165: 219-226, 2004.

VANECKOVA I, VOKURKOVA M, RAUCHOVA H, DOBESOVA Z, PECHANOVA O, KUNES J, VORLICEK J, ZICHA J: Chronic antioxidant therapy lowers blood pressure in adult but not in young Dahl salt hypertensive rats: the role of sympathetic nervous system. Acta Physiol 208: 340-349, 2013.

VASDEV S, GILL V, PARAI S, LONGERICH L, GADAG V: Dietary vitamin E and C supplementation prevents fructose induced hypertension in rats. Mol Cell Biochem 241: 107-114, 2002a.

VASDEV S, GILL V, PARAI S, LONGERICH L, GADAG V: Dietary vitamin E supplementation lowers blood pressure in spontaneously hypertensive rats. Mol Cell Biochem 238: 111-117, 2002 b.

VAZIRI ND, SICA DA: Lead-induced hypertension: role of oxidative stress. Curr Hypertens Rep 6: 314-320, 2004.

VIEL EC, BENKIRANE K, JAVESHGHANI D, TOUYZ RM, SCHIFFRIN EL: Xanthine oxidase and mitochondria contribute to vascular superoxide anion generation in DOCA-salt hypertensive rats. Am J Physiol Heart Circ Physiol 295: H281-H288, 2008.

VIRDIS A, COLUCCI R, VERSARI D, GHISU N, FORNAI M, ANTONIOLI L, DURANTI E, DAGHINI E, GIANNARELLI C, BLANDIZZI C, TADDEI S, DEL TM: Atorvastatin prevents endothelial dysfunction in mesenteric arteries from spontaneously hypertensive rats: role of cyclooxygenase 2-derived contracting prostanoids. Hypertension 53: 1008-1016, 2009.

WAKUI H, DEJIMA T, TAMURA K, UNEDA K, AZUMA K, MAEDA A, OHSAWA M, KANAOKA T, AZUSHIMA K, KOBAYASHI R, MATSUDA M, YAMASHITA A, UMEMURA S: Activation of angiotensin II type 1 receptor-associated protein exerts an inhibitory effect on vascular hypertrophy and oxidative stress in angiotensin II-mediated hypertension. Cardiovasc Res 100: 511-519, 2013.

WANG D, STRANDGAARD S, IVERSEN J, WILCOX CS: Asymmetric dimethylarginine, oxidative stress, and vascular nitric oxide synthase in essential hypertension. Am J Physiol Regul Integr Comp Physiol 296: R195-R200, 2009.

WILCOX CS, PEARLMAN A: Chemistry and antihypertensive effects of tempol and other nitroxides. Pharmacol Rev 60: 418-469, 2008.

YAMAZATO M, OHYA Y, NAKAMOTO M, SAKIMA A, TAGAWA T, HARADA Y, NABIKA T, TAKISHITA S: Sympathetic hyperreactivity to air-jet stress in the chromosome 1 blood pressure quantitative trait locus congenic rats. Am J Physiol Regul Integr Comp Physiol 290: R709-R714, 2006.

ZHOU MS, HERNANDEZ S, I, PAGANO PJ, JAIMES EA, RAIJ L: Reduced NAD(P)H oxidase in low renin hypertension: link among angiotensin II, atherogenesis, and blood pressure. Hypertension 47: 81-86, 2006.

ZICHA J, DOBESOVA Z, KUNES J: Relative deficiency of nitric oxide-dependent vasodilation in salt-hypertensive Dahl rats: the possible role of superoxide anions. J Hypertens 19: 247-254, 2001. 